\title{
RESENHA DE LIVRO: Barata, R. B. (2009). Como e por que as desigualdades sociais fazem mal à saúde. (1a ed.). Rio de Janeiro: Editora Fiocruz.
}

DOI: 10.22289/2446-922X. V4N3A10

Marcus Vinícius Lagares e Oliveira ${ }^{1}$ Constance Rezende Bonvicini Gilmar Antoniassi Junior

Embora os indivíduos façam escolhas que possam implicar em comportamentos sadios ou nocivos a sua saúde essas escolhas estão situadas em contextos familiares, econômicos, culturais, políticos e históricos. Os estilos de vida ou comportamentos individuais são apenas a evidencia mais imediata de todo processo de determinação mediação das desigualdades sócias de saúde. Como e porque as desigualdades sócias fazem mal a saúde? Escrito por Rita Barata, o livro Como e por que as desigualdades sociais fazem mal à saúde? faz parte da coleção Temas em Saúde. Publicado no ano de 2009, pela editora Fiocruz, o livro está subdividido em seis capítulos. Rita Barata é conhecida por publicar trabalhos de referência na Saúde Coletiva, especificamente no que diz respeito ao campo da Epidemiologia Social. Este livro apresenta algumas considerações teóricas sobre o tema das desigualdades sociais em saúde, apontando as correntes e tendências existentes na pesquisa epidemiológica sobre o tema. Ele trata a questão das classes sociais, ou seja, como a posição social de cada indivíduo repercute sobre a sua saúde. Enfoca o tema da renda, isto é, as relações entre riqueza e estado de saúde. Os conteúdos apresentados pela autora ressaltam: $O$ que queremos dizer com desigualdades sociais em saúde? A posição social e seus reflexos sobre a saúde. O ser rico faz bem à saúde? As desigualdades étnicas necessariamente significam racismo? Relações de gênero e saúde: desigualdade ou discriminação? Políticas para o enfrentamento das desigualdades.

No primeiro capítulo a autora apresenta breves considerações teóricas sobre a temática das desigualdades sociais em saúde. Apontando correntes e tendências existentes na pesquisa

\footnotetext{
1 Endereço eletrônico de contato: marcuslagares1@gmail.com Recebido em 12/11/2018. Aprovado pelo conselho editorial para publicação em 17/11/2018.
}

Rev. Psicol Saúde e Debate. Dez., 2018:4(3):110-115. 
epidemiológica sobre o assunto. Partindo deste pressuposto, nos capítulos seguintes a autora aborda as questões referentes às classes sociais. Refletindo de como a posição social de cada indivíduo repercute sobre sua saúde. E sobre a influência da renda, ou seja, as relações entre riqueza e estado de saúde. A autora insere também a discussão sobre a etnia e a discriminação, enquanto categorias importantes da análise do estudo em questão. Por fim, Rita destaca as relações de gênero e a produção da saúde e da doença. Tecendo, ainda comentários sobre as políticas públicas no enfrentamento das desigualdades sociais, para então expor suas considerações e conclusões em torno do tema. Bastante atual o debate evocado por este livro, vem sendo extremamente pertinente a sua leitura e reflexão mesmo para aqueles leitores não especializados. Pois nele é proporcionado uma visão panorâmica acerca do assunto, tendo por base dados de consistentes pesquisas.

No livro uma das primeiras informações que se tem, é que as desigualdades sociais de saúde não são propriamente uma novidade. Já se fala há muito tempo nela, no início do século XIX com o surgimento do capitalismo, uma época muito importante para essas desigualdades começarem a serem tratadas. Segundo a autora aborda no seu livro, o que modifica a percepção das pessoas no início do capitalismo é que a sociedade burguesa pela primeira vez na história, da humanidade defende um lema de igualdade e fraternidade (que é o lema da revolução francesa). Acontece que o capitalismo não permitia a concretização desse lema, na vida real, o capitalismo acirrou o empobrecimento das populações trabalhadoras. Ou seja, contrapondo a uma contradição daquilo que se pregava no nível ideológico, com aquilo que era vida real das pessoas. Neste momento é que surge a medicina social, através da preocupação das pessoas que trabalha na área da saúde, no como enfrentar essa situação que fica muito evidente não tendo, mais como ser escondida.

Em épocas anteriores era como se tal algo fosse natural, que um servo tivesse uma condição pior que um senhor na sociedade burguesa. Mas quando se expõe tais fatores "reflexões" nas condições humanas, tudo começa a ficarem mais relativo estes ideários que existiam nesta época são contrastantes com o dia-a-dia. Porém se buscarmos prolongar tal reflexão realizando um contraponto com os dias de hoje, tais contradições ainda permanecem. Por que hoje em dia se sabe e cada vez mais se fala das desigualdades sócias de saúde. $\mathrm{E}$ muito dificilmente continua mudanças com rapidez. Seguindo o ideal da discussão o buscando a partir do conceito claro (desigualdade social) exposto no livro, refletindo a relação de poder exposta pela sociedade burguesa com o capitalismo, nos dias atuais contemporâneos que vivenciamos, fica eminente o questionamento de, será que não a algum tipo de manipulação 
destes conceitos de acordo com seus objetivos (referenciando ao senhor burguês/ autoridade pública no caso "gestor")?

No livro a autora aborda a discussão reflexiva de que existe nos dias de hoje, os diferentes discursos nos diferentes setores, nas diferentes áreas da saúde e da sociedade. Em que todos na condição de poder falam da desigualdade social ou estratégias de redução das desigualdades sociais, porém poucos fazem. Entre tanto a concepção que se está por traz deste discurso é muito diferente, por exemplo, se você pegar todo o ideário do banco mundial de como ele trabalha com as políticas sociais do mundo, vai estar presente a preocupação com as desigualdades sociais. Porém tal ato, expõe uma forma de pensar a desigualdade social de forma singela e simplificada, não levando em conta o que é de fato que esta desigualdade social produz. Para tanto, a autora expõe que a preocupação dela enquanto pesquisadora da medicina social, da saúde coletiva, são de entender esses processos sociais, estas desigualdades sociais e o que é que resulta nesta desigualdade social. Ou seja, não simplesmente constatar que a desigualdade social existente e trata-la de uma maneira simplificada.

Partindo na reflexão que o livro aborda, em um exemplo simples exposto como ilustração, é que as pessoas sabem que fumar faz mal à saúde, que provavelmente se uma mãe ou uma mulher grávida fuma tal ação pode vir trazer consequência. Mas quando vamos somando a outras variáveis, a gente começa a perceber que isso não é linear. Seria a não linearidade que acabaria com tal resposta não simplista.

A autora chama a atenção para a reflexão de que, seria a linearidade que ajudaria a acabar com tais ações simplistas, pois se o indivíduo entender os problemas, tentando simplificalos a eficácia da intervenção será pequena. O exemplo que a autora traz no livro é altamente relevante, pois fumar é algo altamente nocivo para a saúde em vários aspectos, porém neste aspecto particular de ser fator de risco para a criança é altamente comprovado pelas pesquisas cientificas. Porém, tudo isso é altamente modulado pela classe social, não tem o mesmo impacto para a saúde se a mulher fumante é do proletariado ou é da burguesia. Por que, a mulher tem outras condições de vida que acabam se combinando positivamente ou negativamente, com essa característica do fumar. Se o profissional de saúde, for querer tratar/ equalizar o fumar simplesmente com uma condição de expor querendo convencer as mães do não fumar, o profissional sairá frustrado da ação por que tal aspecto/ação não irá resolver o problema. É claro que é importante (o aspecto do não fumar), sim totalmente importante, mas este aspecto resolve somente um pedaço ou outro pedaço que é a desigualdade social requer uma política muito mais complexa do que convencer as pessoas a não fumarem. 
No entanto deve-se remeter ao pensamento de que os comportamentos individuais são importantes, mas eles são apenas uma parte da compreensão deste processo, da mediação dos determinantes sociais de saúde. Porém, muitas das vezes o indivíduo tem a sensação de que é bombardeado pela frequência das falas como, "mude à sua maneira de viver por que isso resulta no quilo". Claro que quanto mais saudável o indivíduo conseguir levar a vida melhor será para ele. Mas a verdade é que tal ação não basta, o indivíduo não pode ser responsabilizado a este ponto, de que todas as ações que acontecem em sua vida, são por conta da sua incapacidade individual de gerir seus hábitos. É neste ponto que o livro chama a atenção para a reflexão de que aí está a diferença de uma política adotada por países que tem uma política mais liberal (na composição política) de que os indivíduos por si e em si são responsáveis por suas escolhas. Sem considerar que a sociedade em sua organização põe um limite para isso, você não é completamente livre para fazer o que quiser, ir onde quiser e viver como quiser, ou seja, para escolher como viver a sua vida. As limitações existem, fazem parte da organização social e da vida social, do existir do indivíduo na civilização. É a partir deste ponto, que evidencia a ideia da autora em querer chamar a atenção para que exista sim, uma parte da responsabilidade da pessoa (individual), mas até que ponto eu tenho essa liberdade como ser isolado do mundo. Ou seja, o indivíduo é um produto de onde o sujeito nasceu, onde viveu, das experiências intrometidas e experienciadas pelo sujeito em torno do ambiente, das pessoas que o rodeiam. São as escolhas que de fato o sujeito pode fazer e em que medida o comportamento do sujeito é mais resultado, deste constrangimento do meio e em que medida é uma escolha racional.

É notório que existem em determinadas classes este grau de liberdade maior, porém mesmo assim o indivíduo está condicionado culturalmente por uma série de motivos, coisas, como aquilo que valoriza, que o faz integrante deste grupo social, que o diferencia. Enfim todas estas questões elas existem, e são relevantes para saúde, mas elas sozinhas não dão conta. $\mathrm{Na}$ verdade, muitas vezes o indivíduo não percebe e tem a impressão de que o indivíduo faz o que quer, por que vive em uma sociedade democrática, a onde tudo fica muito relativo.

O indivíduo neste ponto acaba sendo muito mais condicionado, do que se imagina e se percebe, e tudo isso resulta em melhor ou pior saúde. E ao não levar todas estas ações reflexivas, novamente se volta ao pensamento linear que diz "você é assim resulta nisso, se você é assim resulta naquilo". Para os profissionais de saúde hoje em dia, os mesmos ainda não conseguem interagirem com seus pacientes/ usuários/ clientes obtendo essa compreensão clara dos aspectos linear no contexto social da saúde. Apesar de estes aspectos parecerem tão óbvio, quando os exemplos são expostos ou discutidos. O livro aborda a reflexão de que a formação profissional não estimula o profissional racionar dentro da complexidade. O profissional é muito 
mais levado a simplificar as questões que a considerar que tudo ou qualquer caso, tem mais ou menos os mesmos condicionamentos e o mesmo desenvolvimento. Quem lida com saúde tem de lidar com a variabilidade entre o biológico e humano, que leve o profissional a pensar, no porque o indivíduo tem aquele determinado comportamento.

A autora dedica dois capítulos do seu livro para falar quanto às etnias e as relações de gênero. Nestes capítulos a autora aborda a relação de preconceito que não está distante tão qual distante da sociedade. Ao ler os capítulos abordados faz a refletir de que todo 0 preconceito faz mal à saúde, os preconceitos e discriminação gera uma exclusão de um grupo, seja qual for o motivo (étnico ou gênero) tal exclusão produz um impacto à saúde que envolve todos os indivíduos de qualquer classe social. Por que gera um mal-estar na sociedade, você pode não ser a vítima da discriminação, mas ao viver em um ambiente onde tal ação existe todos são afetados. Viver em uma sociedade onde isso ocorre torna um problema a saúde, o que não é mais um aspecto individual, mas sim um conjunto de ações. Ainda se naturalizam muitas coisas em torno do envolvimento do indivíduo onde a violência é um indicador de que ainda está escondida na sociedade e que se tem a ideia de que somente é problema de quem sofre e não de toda sociedade em todas as camadas sociais.

Daí então de que todas estas questões na verdade são difíceis de ser transformadas somente com o setor de saúde, embora o setor de saúde tenha sido uma máquina de transformações e ações apontando, agindo de forma que venha a contribuir com a sociedade. Porém o livro faz refletir que chega um determinando momento em que o setor de saúde fica impotente se outras transformações sociais não acontecerem, pois, o setor de saúde sozinho não irá conseguir implicar em mudança de atitudes se não houver uma mobilização social. Este seria o ponto fundamental da reflexão global abordada no texto, que chega um momento em que no enfrentamento das desigualdades são inevitáveis as políticas intersetoriais.

O setor de saúde tem uma parcela para fazer e acontecer (e vale ressaltar que vem fazendo através do SUS) mas o SUS/ setor de saúde sozinho não resolve. Pois embora tenha a garantia do acesso ao setor de saúde a todos, você não consegue somente com estes aspectos equalizar/ solucionar os problemas das desigualdades sociais, que são geradas na própria organização da sociedade. O que o sistema de saúde consegue fazer é minimizar, não potencializar a desigualdade, não agir discriminando grupos, todas estas ações são fundamentais, porém sozinho não irá equacionar o problema e precisa de políticas. E o SUS vem sendo um esforço para equalizar as demandas das desigualdades sociais na saúde, apontando os locais e implementando medidas alternativas dos princípios dos SUS. 
Torna viável abordar na reflexão proposta pelo livro que o SUS enquanto princípio de universalidade, equidade e integralidade, atender a todos e atender a todas as questões, faz necessário refletir para o aspecto da equidade pois talvez seja ela em seu conceito amplo da definição que faz pensar no princípio, para solucionar as desigualdades sociais de saúde. Em torno disso, pensar em equidade remete ao exercício profissional de pensar na definição filosófica da palavra, por Aristóteles que é a ideia de que você não deve querer além do sujeito, ou seja, você deve pedir a cada um de acordo com sua capacidade e suas possibilidades. E aí está a ideia do SUS de que não vai dar igual para todos e sim dar mais para quem precisa mais, e este é o grande desafio. Porém a ideia da igualdade é mais simples no que faz pensar em dividir tudo que temos por todos, mas isso não resolve o problema pois uma parcela da sociedade já tem mais e se der mais irão ter mais. O que se faz contraditório pois praticar a equidade pode gerar a desigualdade, partindo do ponto de vista reflexivo da justiça social, mas é neste ponto que está a grande reflexão ao princípio da equidade para a desigualdade social na saúde, pois a pessoas serão tratadas desigualmente partindo das desigualdades já existentes.

Para finalizar toda a ideia reflexiva, no início do livro a autora deixa claro que igualdades e diferenças são muito bem-vindas desde que elas não sejam fruto de uma injustiça social. Indico esta obra a todas as pessoas que assim como eu, tenham a possibilidade de serem diferentes e a sociedade ser diferente e viver com saúde.

Rev. Psicol Saúde e Debate. Dez., 2018:4(3):110-115. 